Temoteus Prasetyo Hadi Atmoko, Ihsan Budi Santoso: STRATEGI PENGEMBANGAN

KAWASAN AIRPORT CITY MELALUI PENINGKATAN SDM PERHOTELAN DAN

RESTORAN DI KABUPATEN KULON PROGO

\title{
STRATEGI PENGEMBANGAN KAWASAN AIRPORT CITY MELALUI PENINGKATAN SDM PERHOTELAN DAN RESTORAN DI KABUPATEN KULON PROGO
}

\author{
T. Prasetyo Hadi Atmoko ${ }^{(1)}$, Ihsan Budi Santoso ${ }^{(2)}$ \\ (1) (2) Program Studi Perhotelan Akademi Pariwisata Yogyakarta \\ prasplg@gmail.com, rasahgetun86@gmail.com \\ Submitted: 10 August 2019 Revised: 29 August 2019 \\ Accepted: 1 September 2019
}

\begin{abstract}
ABSTRAK
Penelitian ini bertujuan untuk mengetahui sikap masyarakat terhadap pengembangan kawasan Airport City, strategi pengembangan pariwisata dan untuk mengetahui strategi peningkatan SDM bidang perhotelan dan restoran. Jenis data yang dikumpulkan adalah data kualitatif, dengan analisis SWOT. Berdasarkan wawancara dengan 40 responden yang terdiri dari 31 orang anggota PHRI dan 9 orang tokoh masyarakat, 30 orang menyatakan sangat setuju dengan dibangunnya bandara YIA di Kulon Progo, dan 10 orang menyatakan setuju. Pengembangan pariwisata kawasan Airport City dilakukan dengan membentuk BPC PHRI Cabang Kulon Progo sehingga berdampak pada pertumbuhan hotel dan restoran yang ada di Kulon Progo. Berdasarkan gambar matrik SWOT, hasil analisis terpetakan pada kuadran I kondisi yang kuat dan berpeluang, rekomendasi strategi yang diberikan adalah progresif, yaitu berfokus pada strategi SO, dengan meningkatkan sinergi antara PHRI dengan dinas terkait dalam pelatihan pengolahan makanan untuk chef dan barista, serta bimtek online single Submission (OSS).
\end{abstract}

Kata Kunci: Airport City, Pengembangan, Peningkatan SDM

\section{DEVELOPMENT STRATEGY OF THE AIRPORT CITY AREA THROUGH HUMAN RESOURCE IMPROVEMENT OF HOSPITALITY AND RESTAURANT IN KULON PROGO DISTRICT}

\section{ABSTRACT}

This study aims to know the attitude of the community towards the development of the Airport City area, tourism development strategies and to find out strategies for improving the Human Resource in the hotel and restaurant sector. The type of data collected is qualitative data, with SWOT analysis. Based on interviews with 40 respondents consisting of 31 members of PHRI and 9 community leaders, 30 respondents stated strongly agree with the construction of the YIA airport in Kulon Progo, and 10 respondents stated agreed. The Airport City tourism development was carried out by forming a BPC PHRI (A Branch Leadership Management's The Association Of Hotels And Restaurants Indonesia) Kulon Progo Branch so that it affected to the growth of hotels and restaurants in Kulon Progo. Based on the SWOT matrix image, the results of the analysis are mapped to first quadrant, strong conditions and have a chance, the recommendations of the strategy given are progressive, namely focusing on the SO strategy. by increasing the synergy between PHRI and related agencies in food processing training for chefs and baristas, as well as technical guidance of online single Submission (OSS).

Keywords: Airport City, Development, Human Resource Improvement 


\section{PENDAHULUAN}

Berwisata sudah merupakan trend bagi masyarakat. Masyarakat cenderung akan menyisihkan sebagian waktunya untuk melakukan kegiatan wisata menghilangkan kejenuhannya. Di sela-sela melakukan kegiatan wisata, wisatawan pasti akan menyempatkan untuk berburu makanan dan minuman khas daerah yang dituju tersebut (Widyaningsih, 2013). Tujuan pengembangan destinasi pariwisata adalah mengembangkan destinasi pariwisata yang berdaya saing serta dapat memberikan kontribusi yang signifikan terhadap perekonomian nasional dan kesejahteraan masyarakat (UU kepariwisataan no 10 tahun 2009).

Yogyakarta International Airport (YIA) di Kulon Progo Daerah Istimewa Yogyakarta diharapkan mampu menjadikan perekonomian di daerah sekitar semakin meningkat. Salah satu yang perlu disiapkan adalah Sumber Daya Manusia di Kulon Progo supaya memiliki skill terutama bidang hospitality agar nantinya dapat terserap dan mendapat manfaat dari dikembangkannya proyek YIA. Bupati Kulon Progo dr H Hasto Wardoyo SpOG (K) dalam pelantikan PHRI cabang Kulon Progo mengingatkan bahwa PHRI DIY mempunyai tugas yang tidak ringan dalam peran sertanya meningkatkan kunjungan pariwisata. Apalagi nantinya bandara baru sudah beroperasi dan akan adanya kota bandara (Airport City) di kawasan Kulon Progo. Kehadiran bandara baru diprediksi mampu tingkatkan kunjungan wisata dua kali lipat dibandingkan sebelum ada bandara (Widiastuti, 2018).

Bapak KRHT Drs Istidjab M. Danunagoro, MM selaku Ketua PHRI DIY menyatakan siap menyambut bandara dengan pemberdayaan masyarakat Kulon Progo untuk meningkatkan kompetensi serta memprioritaskan pembenahan dan peningkatan Sumber Daya Manusia (SDM) di bidang perhotelan dan restoran, sehingga akan meningkatkan pelayanan terhadap wisatawan.

Berdasarkan latar belakang yang sudah diuraikan di atas, dapat ditarik rumusan masalah sebagai berikut:

1. Bagaimana sikap masyarakat terdampak proyek bandara terhadap pengembangan Airport City di Kabupaten Kulon Progo?

2. Bagaimana pengembangan pariwisata kawasan Airport City di Kabupaten Kulon Progo?

3. Bagaimana strategi PHRI dalam meningkatkan sumber daya manusia bidang Perhotelan dan Restoran?

Tujuan dari penelitian ini adalah untuk mengetahui sikap masyarakat terdampak proyek bandara Kulon Progo terhadap pengembangan Airport City di Kabupaten Kulon Progo, untuk mengetahui strategi pengembangan pariwisata kawasan Airport City di Kabupaten Kulon Progo dan untuk mengetahui bagaimana upaya peningkatan sumber daya manusia bidang Perhotelan dan Restoran oleh PHRI DIY. Manfaat teoritis dari penelitian ini adalah sebagai penambah ilmu pengetahuan tentang perhotelan dan restoran. Sedangkan manfaat praktisnya, penelitian ini dapat digunakan sebagai perumusan strategi dalam pengembangan pariwisata bidang perhotelan dan restoran.

\section{LANDASAN TEORI}

Penelitian ini merupakan penelitian baru, belum pernah dilakukan oleh siapapun.

Penelitian yang relevan dangan penelitian ini adalah

\section{Tabel 1}

Penelitian Yang Relevan

\begin{tabular}{llll}
\hline No & \multicolumn{1}{c}{ Judul } & Metode & \multicolumn{2}{c}{ Hasil } \\
\hline 1 & Model Peningkatan & Deskriptif & Hasil penelitian terhadap karyawan front office, \\
& $\begin{array}{l}\text { Kompetensi } \\
\text { Sumberdaya Manusia }\end{array}$ & Kualitatif & $\begin{array}{l}\text { tatagraha, pramusaji, dan cook menunjukkan } \\
\text { bahwa kompetensi yang dimiliki belum }\end{array}$ \\
\hline
\end{tabular}




\begin{tabular}{|c|c|c|c|}
\hline & 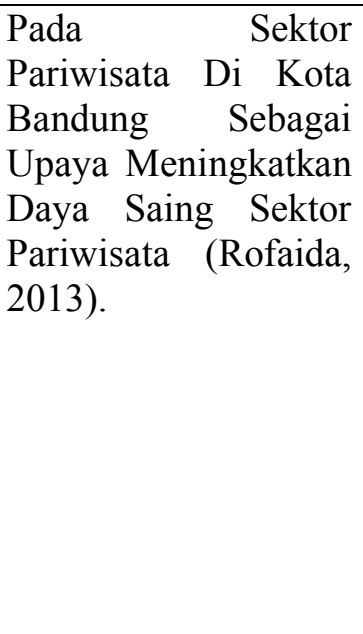 & & $\begin{array}{l}\text { memenuhi standar yang ditetapkan SKKNI untuk } \\
\text { bidang hotel dan restoran. Strategi peningkatan } \\
\text { kompetensi SDM yang diajukan terdiri dari: (1). } \\
\text { Peningkatan kapasitas lembaga diklat (2). } \\
\text { Peningkatan kompetensi SDM melalui pelatihan, } \\
\text { dan (3) Peningkatan kompetensi SDM melalui } \\
\text { program sertifikasi dan standarisasi. Peningkatan } \\
\text { kompetensi SDM ditentukan oleh tiga faktor, } \\
\text { yaitu: industri, kebijakan pemerintah, dan institusi } \\
\text { pendidikan. Pemetaan dan analisis peran sistem } \\
\text { 'Triple Helix' (industri, pemerintah dan } \\
\text { akademisi) akan menghasilkan model } \\
\text { peningkatan kompetensi SDM sektor hotel dan } \\
\text { restoran. }\end{array}$ \\
\hline 2 & $\begin{array}{lr}\text { Peningkatan } \\
\text { Kompetensi } & \text { SDM } \\
\text { Bidang } & \text { Tata } \\
\text { Hidangan } & \text { Melalui } \\
\text { Pelatihan Pada } & \text { Usaha } \\
\text { Akomodasi } & \text { Hotel } \\
\text { Bintang Tiga } & \text { Di } \\
\text { Kabupaten } & \text { Bogor } \\
\text { (Tanuwijaya, 2015). }\end{array}$ & $\begin{array}{l}\text { Deskriptif } \\
\text { Kualitatif }\end{array}$ & $\begin{array}{l}\text { Hasil penelitian ini diharapkan dapat memberikan } \\
\text { kontribusi kepada pihak pemerintah Kabupaten } \\
\text { Bogor-Dinas Kebudayaan Dan Pariwisata } \\
\text { Kabupaten Bogor, dan kepada pengelola usaha } \\
\text { akomodasi hotel bintang tiga di Kabupaten Bogor } \\
\text { agar menemukenali kondisi SDM pada usaha } \\
\text { akomodasi serta kompetensi yang dimilikinya. } \\
\text { Dengan diketahuinya kondisi tersebut, } \\
\text { pemerintah diharapkan dapat mengantisipasi } \\
\text { kebutuhan pendidikan dan pelatihan SDM yang } \\
\text { tepat guna pada usaha sarana akomodasi pada } \\
\text { masa depan. }\end{array}$ \\
\hline
\end{tabular}

Sumber: Olahan Peneliti (2019)

Menurut Nawawi dalam Gaol (2014), Sumber Daya Manusia (SDM) adalah orang yang bekerja dan berfungsi sebagai asset organisasi/perusahaan yang dapat dihitung jumlahnya (kualitatif), dan SDM merupakan potensi yang menjadi penggerak organisasi. Sedangkan menurut Sutrisno (2014) Sumber Daya Manusia merupakan satu satunya sumber daya yang memiliki akan perasaan, keinginan, keterampilan, pengetahuan, dorongan, daya dan karya. Jadi, Sumber Daya Manusia merupakan aset terpenting yang harus dikelola untuk mengembangkan sebuah usaha. Penyediaan jasa akomodasi merupakan salah satu bisnis dalam bidang pariwisata yang menyediakan pelayanan penginapan yang dapat dilengkapi dengan pelayanan pariwisata lainnya. Salah satu jenis akomodasi yang menyediakan pelayanan penginapan adalah hotel. Hotel didefinisikan sebagai suatu organisasi pelayanan jasa yang menyediakan sarana akomodasi, makanan dan minuman, serta fasilitas lain yang dikelola dengan tujuan mendapatkan keuntungan (Atmoko\&Heni, 2018). Memenuhi semua harapan tamu bukanlah pekerjaan yang mudah, bahkan dapat dikatakan tidak mungkin, namun ada beberapa pendekatan yang dapat digunakan oleh para pegawai hotel di dalam upayanya memenuhi harapan para tamu, yaitu memiliki mental wirausaha dan memiliki pola pikir positif (Sujatno, 2009).

Menurut Peraturan Menteri Pariwisata Dan Ekonomi Kreatif Republik Indonesia Nomor 11 Tahun 2014 Tentang Standar Usaha Restoran, standar usaha restoran adalah rumusan kualifikasi usaha restoran 
dan/atau klasifikasi usaha restoran yang mencakup aspek produk, pelayanan dan pengelolaan usaha restoran. Dalam meningkatkan aspek produk, pelayanan dan pengelolaan tersebut tentu saja diperlukan pengembangan SDM berupa pelatihan bidang restoran. Dengan adanya keterampilan yang cukup, maka kinerja yang dihasilkan akan lebih baik sehingga akan berdampak positif bagi perkembangan usahanya (Adriyanti dan Agung, 2018).

\section{METODE PENELITIAN}

Jenis data yang dikumpulkan dalam penelitian ini adalah data kualitatif, yaitu data berupa keterangan atau informasi mengenai pengembangan pariwisata di Kawasan Airport City Kulon Progo. Sumber data yang digunakan adalah sumber data primer, yaitu sumber data yang diperoleh pertama langsung dari objek penelitian, yaitu keterangan atau informasi mengenai pendapat tokoh masyarakat setempat sebanyak 9 orang, dan 31 orang yang tergabung dalam PHRI. Sumber data sekunder yaitu data yang diperoleh berupa data yang telah jadi, yang diperoleh dari dokumentasi. Teknik Pengumpulan data yang digunakan adalah melakukan wawancara dengan pihak terkait seperti Dinas Pariwisata, PHRI dan masyarakat sekitar, observasi mengamati langsung pengembangan Airport City, dokumentasi untuk memperoleh data melalui dokumendokumen yang berhubungan dengan penelitian dan studi pustaka untuk mendapatkan pengetahuan sebagai landasan teori. Tehnik analisis yang digunakan yaitu analisis deskriptif untuk mengetahui gambaran objek penelitian dan Analisis SWOT (Strengths, Weaknesses, Opportunities, dan Threats). Analisis SWOT digunakan menganalisis data untuk memperoleh alternatif strategi dalam pengembangan kawasan Airport City di Kulon Progo. Analisis ini digunakan untuk memaksimalkan kekuatan dan peluang, yang secara bersamaan dapat meminimalkan kelemahan dan ancaman.
SWOT merupakan suatu analisis yang dapat dipergunakan untuk merumuskan strategi, yang terdiri dari analisis kekuatan, kelemahan, peluang, dan ancaman yang dihadapi untuk mencapai tujuan. Untuk dapat mengembangkan alternatif strategi dilakukan dengan alat bantuan analisis SWOT (Strengths, Weaknesses, Opportunities, dan Threats). Setelah semua informasi terkumpul, baik analisis lingkungan internal maupun analisis eksternal, tahap berikutnya adalah mengembangkan alternatif strategi. Dalam merumuskan strategi dapat dipergunakan alat bantu berupa matrik SWOT yang dapat menggambarkan bagaimana peluang (opportunities) dan ancaman (threats) eksternal yang dihadapi yang selanjutnya disesuaikan dengan kekuatan (strengths) dan kelemahan (weaknesses) internal yang dimilikinya. Analisis SWOT dapat dilihat dalam tabel 2 berikut ini:

\section{Tabel 2}

Analisis SWOT

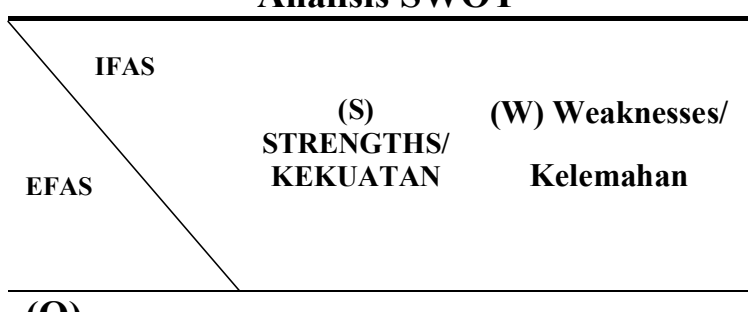

\begin{tabular}{lll}
\hline Op) & & \\
Opportunit & Strategi & Strategi WO \\
ies/ & SO & Mengembangk \\
Peluang & Mengemba & an suatu \\
& ngkan suatu & strategi dalam \\
& strategi & memanfaatkan \\
dalam & peluang (O) \\
& memanfaat & untuk \\
kan & mengatasi \\
& kekuatan(S) & kelemahan \\
& untuk & (W). \\
& mengambil & \\
& manfaat & \\
dari & \\
& peluang (O) \\
\end{tabular}

(T)

Threats/ Strategi ST Strategi WT 
Temoteus Prasetyo Hadi Atmoko, Ihsan Budi Santoso: STRATEGI PENGEMBANGAN

KAWASAN AIRPORT CITY MELALUI PENINGKATAN SDM PERHOTELAN DAN

RESTORAN DI KABUPATEN KULON PROGO

\begin{tabular}{lll}
\hline Ancaman & Mengemba & Mengembangk \\
ngkan suatu & an suatu \\
strategi & strategi dalam \\
dalam & mengurangi \\
memanfaat & kelemahan \\
kan & (W) dan \\
kekuatan & menghindari \\
(S) untuk & ancaman (T) \\
menghindar & \\
i ancaman & \\
(T) &
\end{tabular}

Sumber: Atmoko \& Heni (2018)

\section{PEMBAHASAN}

\section{Sikap masyarakat} pengembangan Airport City di Kabupaten Kulon Progo

Responden dalam penelitian ini yaitu 40 orang masyarakat terdampak proyek bandara, yaitu 31 orang tergabung dalam PHRI dan 9 orang merupakan tokoh masyarakat. Berdasarkan wawancara, 30 orang menyatakan sangat setuju dengan pengembangan Airport City di Kulon Progo, dan 10 orang menyatakan setuju. Hal tersebut ditunjukkan dengan merelakan tanahnya untuk dijadikan bandara. Selain itu, responden juga mengaku bahwa ada peningkatan pelanggan di rumah makan dan restoran mereka serta meningkatnya tingkat hunian kamar.

Persentase sikap masyarakat dapat dilihat dalam gambar berikut:

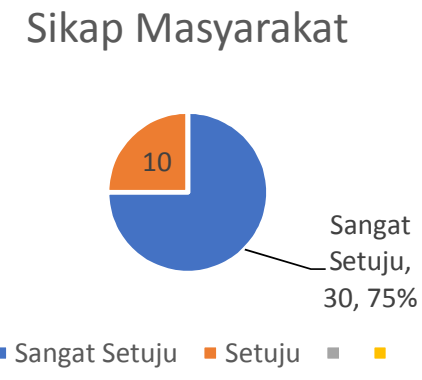

Gambar 1. Sikap masyarakat Sumber: Olahan peneliti (2019)

Strategi Pengembangan Pariwisata Kawasan Airport City di Kabupaten Kulon Progo
Pengembangan pariwisata kawasan Airport City dilakukan dengan membentuk BPC PHRI Cabang Kulon Progo dengan anggota pengelola hotel, rumah makan dan pendidik bidang pariwisata di Kabupaten Kulon Progo. Dengan pembentukan BPC PHRI Cabang Kulon Progo ini berdampak pada pertumbuhan hotel dan restoran yang ada di Kulon Progo, dapat dilihat dalam tabel berikut ini:

Tabel 3

Pertumbuhan Hotel dan restoran

\begin{tabular}{|c|c|c|c|}
\hline No & Hotel & Penginapan & $\begin{array}{l}\text { Rumah } \\
\text { Makan }\end{array}$ \\
\hline 1 & $\begin{array}{l}\text { Hotel } \\
\text { King }\end{array}$ & Romanza & Pandan Sari \\
\hline 2 & $\begin{array}{l}\text { Wisma } \\
\text { Hotel }\end{array}$ & Larasati & $\begin{array}{l}\text { Waroeng } \\
\text { Joglo }\end{array}$ \\
\hline 3 & $\begin{array}{l}\text { Hotel } \\
\text { Primitif }\end{array}$ & Palma & Bu Hartin \\
\hline 4 & & Sederhana & $\begin{array}{l}\text { Ayam } \\
\text { Goreng } \\
\text { Bugisan }\end{array}$ \\
\hline 5 & & Lovina & $\begin{array}{l}\text { Oza } \\
\text { Aloevera }\end{array}$ \\
\hline 6 & & Virgo & $\begin{array}{l}\text { Cemara } \\
\text { Indah }\end{array}$ \\
\hline 7 & & $\begin{array}{l}\text { Kembang } \\
\text { Lombok }\end{array}$ & Yu Gun \\
\hline 8 & & Gita & $\begin{array}{l}\text { Ingkung } \\
\text { Jawa }\end{array}$ \\
\hline 9 & & Pesona & $\begin{array}{l}\text { Pring } \\
\text { Petung }\end{array}$ \\
\hline 10 & & Boulevard & $\begin{array}{l}\text { Mbah } \\
\text { Cempluk }\end{array}$ \\
\hline 11 & & Sari Laut & Kopiland \\
\hline 12 & & Dinah Laut & Kopi NYIA \\
\hline 13 & & Langen laut & Sehati \\
\hline 14 & & & Hikmah \\
\hline
\end{tabular}

Perhimpunan Hotel dan Restoran Indonesia (PHRI), juga dikenal sebagai Indonesia Hotel \& Restaurant Association (IHRA), adalah asosiasi non-profit dari pemilik hotel dan restoran serta para profesional yang memfokuskan kegiatannya untuk pengembangan dan pertumbuhan sektor-sektor penting industri pariwisata di 
indonesia. Selama bertahun tahun, PHRI telah tumbuh menjadi sebuah asosiasi penting yang dekat dengan pemerintah dan sektor swasta terkait, menyajikan aspirasi serta tantangan dari industri kepada pemerintah sehingga tercipta kebijakan yang terstruktur sesuai dengan kebutuhan nyata industri. Di dalam keanggotaan PHRI antara lain, hotel, restoran dan industri terkait termasuk pemasok dan lembaga pendidikan pariwisata.

Dibentuknya PHRI mempunyai tujuan ikut serta mewujudkan cita-cita bangsa sebagaimana dimaksud dalam jiwa dan semangat UUD 1945, dalam hal pembinaan PHRI menempatkan diri sebagai satu-satunya wadah hotel dan restoran dan mitra pemerintah dalam pembangunan serta turut melaksanakan pembangunan nasional pada umumnya dan pembangunan pariwisata pada khususnya sehingga mampu berperan serta, baik nasional maupun internasional. Untuk mencapai tujuannya, maka PHRI berusaha untuk :

1. Membina dan mengembangkan badanbadan usaha yang bergerak di bidang jasa perhotelan, usaha jasa makanan dan minuman serta lembaga pendidikan pariwisata.

2. Turut serta mengembangkan potensi kepariwisataan nasional secara serasi, seimbang, selaras antara pemerintah swasta dan masyarakat.

3. Memajukan dan menumbuhkan semangat kepariwisataan dalam kehidupan pribadi, masyarakat dan pada seluruh potensi bangsa.

4. Membantu dan membina para anggota, memberikan perlindungan, menerima masukan, memberikan bimbingan dan konsultasi serta pendidikan dan pelatihan utuk meningkatkan mutu anggota.

5. Menggalang kerjasama dan solidaritas sesama anggota dan seluruh unsur serta potensi kepariwisataan nasional maupun internasional.

6. Berperan aktif dalam kegiatan promosi di dalam dan di luar negeri, untuk meningkatkan dan memantapkan iklim usaha kepariwisataan.

7. Melakukan kegiatan penelitian, perencanaan dan pengembangan usaha.

8. Melakukan koordinasi dan kerjasama dengan berbagai asosiasi profesi jasa pariwisata lainnya.

9. Memajukan dan mengembangkan industri kepariwisataan dalam arti kata yang seluas-luasnya.

Strategi PHRI dalam Meningkatkan Sumber Daya Manusia bidang Perhotelan dan Restoran di Kabupaten Kulon Progo

Pembangunan pariwisata diharapkan menjadi tonggak dalam pembangunan nasional sehingga diperlukan strategi untuk meningkatkan pengetahuan dan keterampilan SDM pariwisata. Dalam pemilihan strategi untuk meningkatkan SDM bidang perhotelan dan restoran di Kabupaten Kulon Progo, data yang diperoleh diolah dan diformulasikan dalam analisis SWOT agar kekuatan dan peluang dapat meminimalkan kelemahan dan ancaman, sehingga akan diperoleh strategi untuk pengembangan Airport City bidang perhotelan dan restoran. Perumusan strategi dilakukan dengan menganalisis faktor internal dan faktor eksternal terlebih dahulu, yaitu sebagai berikut:

1. Matrik IFAS

Analisis dengan matriks Internal Factors Analysis Summary (IFAS) dilakukan setelah strategi internal diidentifikasi. Menurut Utama (2012) dalam analisis IFAS dilakukan tahap-tahap sebagai berikut:

a. Membuat daftar faktor-faktor internal, yaitu kekuatan (strengths) dan kelemahan (weaknesses).

b. Melakukan pembobotan dengan metode perbandingan berpasangan, sehingga total bobot sama dengan satu.

c. Memberikan peringkat (rating) antara 1 sampai 4 bagi masing-masing faktor kekuatan dan kelemahan, dengan nilai 1 (sangat lemah), 2 (tidak begitu lemah), 3 (cukup kuat), 4 (sangat kuat). Nilai (rating) mengacu pada kondisi objek penelitian. 
Temoteus Prasetyo Hadi Atmoko, Ihsan Budi Santoso: STRATEGI PENGEMBANGAN

KAWASAN AIRPORT CITY MELALUI PENINGKATAN SDM PERHOTELAN DAN

\section{RESTORAN DI KABUPATEN KULON PROGO}

d. Mengalikan bobot dan rating dari masing-masing faktor untuk menentukan nilai skornya.

e. Jumlahkan semua skor untuk mendapatkan skor total bagi objek yang dinilai. Jika nilainya di bawah 1,5 menandakan bahwa secara internal,

Tabel 4

Matrik IFAS

\section{Faktor Strategi Internal}

objek berada di posisi sangat lemah, sedangkan nilai yang berada di atas 2,5 menunjukkan posisi internal yang sangat kuat. Matrik IFAS dapat dilihat pada tabel 4 sebagai berikut:

\section{Kekuatan}

\begin{tabular}{lllc}
\hline 1. Adanya kelompok pemberdayaan masyarakat & 0,14 & 3 & 0,42 \\
\hline $\begin{array}{l}\text { 2. Masyarakat mempunyai kreativitas bidang kuliner } \\
\text { 3. Sebagian SDM sudah memiliki sertifikat kompetensi } \\
\text { bidang pengolahan makanan }\end{array}$ & 0,14 & 3 & 0,42 \\
\hline $\begin{array}{l}\text { 4. Adanya motivasi masyarakat untuk mengembangkan } \\
\text { pariwisata Kulon Progo }\end{array}$ & 0,11 & 3 & 0,72 \\
\hline $\begin{array}{l}\text { Skor Indikator Kekuatan } \\
\text { Kelemahan }\end{array}$ & $\mathbf{0 , 5 7}$ & 0,33 \\
\hline $\begin{array}{l}\text { 1. Masih sedikit warga lokal Kulon Progo yang memiliki } \\
\text { basic Pariwisata }\end{array}$ & 0,06 & $\mathbf{1 , 8 9}$ \\
\hline $\begin{array}{l}\text { 2. Sebagian usaha jasa pariwisata baik penginapan, wisma, } \\
\text { hotel maupun rumah makan belum melengkapi usahanya } \\
\text { dengan perijinan berupa tanda daftar usaha pariwisata } \\
\text { (TDUP) }\end{array}$ & 0,16 & 3 & 0,12 \\
\hline $\begin{array}{l}\text { 3. Peserta pelatihan tidak tahan dengan waktu pelatihan } \\
\text { yang cukup lama }\end{array}$ & 0,09 & 2 & 0,48 \\
\hline 4. Masyarakat kurang memahami teknologi & 0,12 & 3 & 0,36 \\
\hline Skor Indikator Kelemahan & $\mathbf{0 , 4 3}$ & $\mathbf{1 , 0 0}$ & $\mathbf{1 , 1 4}$ \\
\hline Total IFAS & & $\mathbf{3 , 0 3}$ \\
\hline
\end{tabular}

Sumber: Olahan Peneliti (2019)

2. Analisis Matrik EFAS

Analisis dengan matriks External Factors Analysis Summary (EFAS) dilakukan setelah strategi eksternal diidentifikasi. Menurut Utama (2012) dalam analisis EFAS dilakukan tahap-tahap sebagai berikut:

a. Membuat daftar faktor-faktor eksternal, yaitu peluang (opportunity) dan ancaman (threat).

b. Melakukan pembobotan dengan metode perbandingan berpasangan, sehingga total bobot sama dengan satu.

c. Memberikan peringkat (rating) antara 1 sampai 4 bagi masing-masing peluang dan ancaman, dengan nilai 1 (tidak berpeluang), 2 (tidak begitu berpeluang), 3 (cukup berpeluang), 4 (sangat berpeluang). Nilai (rating) mengacu pada kondisi objek penelitian.

d. Mengkalikan bobot dan rating dari masing-masing faktor untuk menentukan nilai skornya.

e. Jumlahkan semua skor untuk mendapatkan skor total bagi objek yang dinilai. Jika nilainya di bawah 2,5 menandakan bahwa secara eksternal, objek berada di posisi terancam. Matrik EFAS dapat dilihat dalam tabel 5 sebagai berikut: 
Tabel 5

Matrik EFAS

\begin{tabular}{llll}
\hline Faktor Strategi Eksternal & Bobot & Rating & Nilai \\
\hline Peluang & & & \\
\hline $\begin{array}{l}\text { 1. Bandara Internasional akan meningkatkan } \\
\text { kunjungan wisatawan mancanegara }\end{array}$ & 0,20 & 4 & 0,80 \\
\hline $\begin{array}{l}\text { 2. Dengan adanya pengembangan Airport City } \\
\text { hampir semua penginapan, hotel atau wisma } \\
\text { yang ada di sekitar area full booking }\end{array}$ & 0,11 & 3 & 0,33 \\
\hline $\begin{array}{l}\text { 3. Pembentukan BPC PHRI Kulon Progo } \\
\text { 4. Adanya kebijakan pemerintah dalam program } \\
\text { peningkatan SDM Kulon Progo }\end{array}$ & 0,16 & 4 & 0,64 \\
\hline Skor Indikator Peluang & 3 & 0,36 \\
\hline $\begin{array}{l}\text { 1. Banyaknya penginapan ilegal yang harganya } \\
\text { lebih murah }\end{array}$ & 0,14 & 3 & 0,42 \\
\hline $\begin{array}{l}\text { 2. Belum adanya kejelasan berkaitan dengan } \\
\text { pengaturan tata ruang oleh propinsi DIY } \\
\text { sehingga rencana mendirikan usaha jasa } \\
\text { akomodasi di kawasan tersebut menjadi } \\
\text { tertunda. }\end{array}$ & 0,17 & 4 & 0,68 \\
\hline $\begin{array}{l}\text { Adanya investor asing yang lebih menguasai } \\
\text { bidang pariwisata }\end{array}$ & 0,06 & 2 & 0,12 \\
\hline $\begin{array}{l}\text { 4. Masuknya budaya asing membuat generasi } \\
\text { muda kurang berminat terhadap kuliner } \\
\text { berbahan lokal }\end{array}$ & 0,04 & 1 & 0,04 \\
\hline $\begin{array}{l}\text { Skor Indikator Ancaman } \\
\text { Total EFAS }\end{array}$ & $\mathbf{0 , 4 1}$ & & $\mathbf{1 , 2 6}$ \\
\hline
\end{tabular}

Sumber: Olahan Peneliti (2019)

Analisis tabel 4 menunjukkan bahwa untuk indikator kekuatan (strength) mempunyai total nilai skor 1,89 sedangkan kelemahan (weakness) mempunyai total nilai skor 1,14. Analisis tabel 5, tabel EFAS, menunjukkan bahwa indikator peluang (opportunities) mempunyai total nilai skor 2,13, dan indikator ancaman (threats) 1,26. Dari analisis tersebut, diketahui nilai strength di atas weakness $+0,75$ dan nilai opportunities di atas nilai threats $+0,87$. Hasil identifikasi indikator tersebut dapat digambarkan diagram SWOT pada gambar berikut ini:

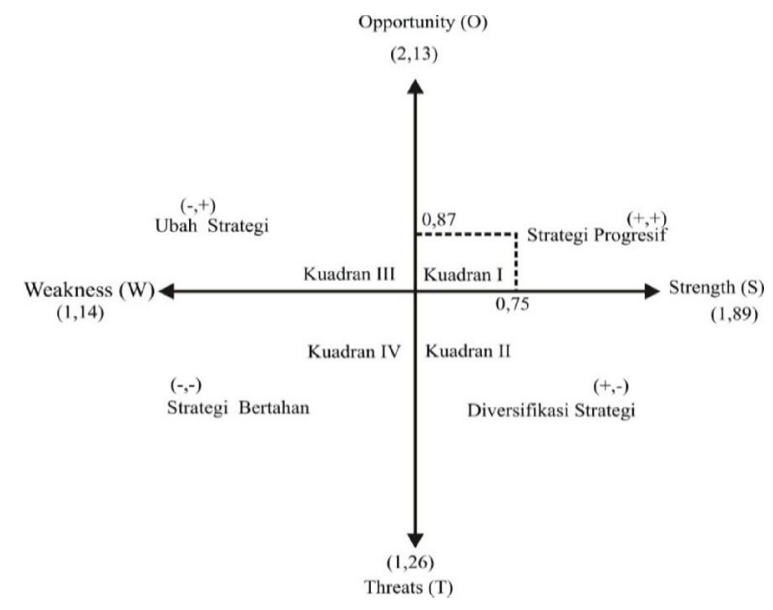

Gambar 2. diagram SWOT

Sumber: Olahan Peneliti (2019) 
Temoteus Prasetyo Hadi Atmoko, Ihsan Budi Santoso: STRATEGI PENGEMBANGAN

KAWASAN AIRPORT CITY MELALUI PENINGKATAN SDM PERHOTELAN DAN

RESTORAN DI KABUPATEN KULON PROGO

Berdasarkan nilai total masing-masing indikator dapat digambarkan rumusan matrik SWOT dalam tabel 6 sebagai berikut:

Tabel 6

Kombinasi Matrik SWOT

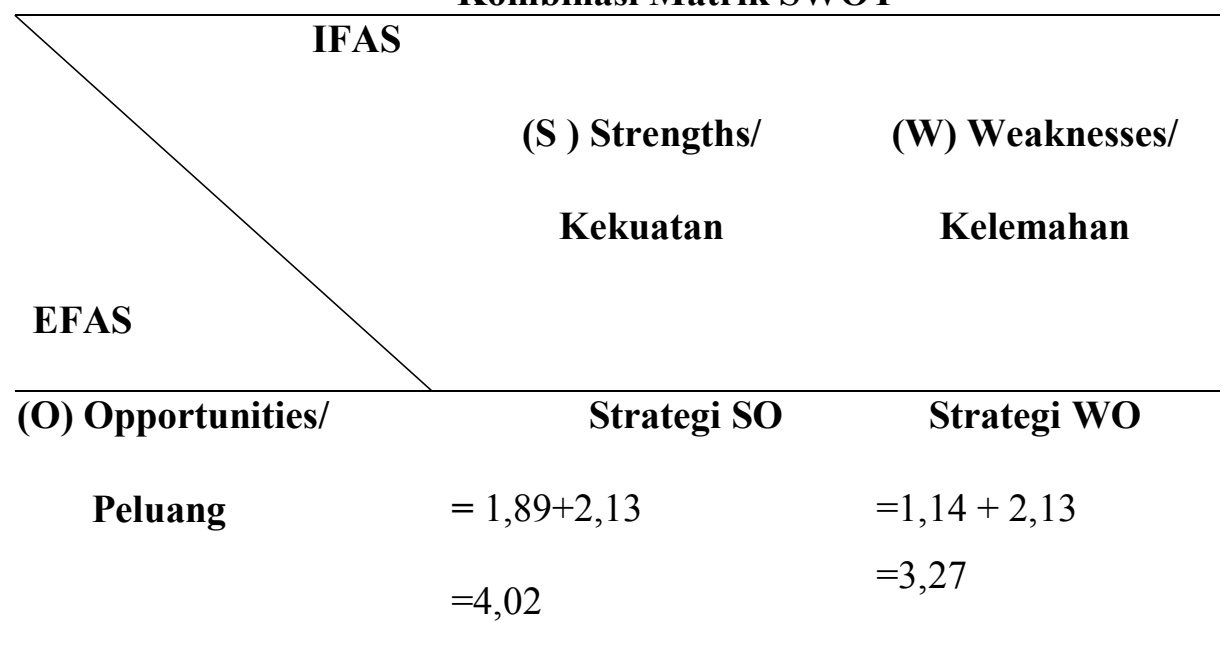

(T) Threats/ Ancaman

Strategi ST

Strategi WT

$\begin{array}{ll}=1,89+1,26 & =1,14+1,26 \\ =3,15 & =2,4\end{array}$

Sumber : Olahan Peneliti (2019)

Strategi Pengembangan SDM Oleh PHRI

Berdasarkan analisis Matrik IFAS dan EFAS pada tabel 4 dan 5 disusun matriks SWOT untuk menganalisis rumusan analisis strategi SO, WO, ST dan WT dapat dilihat dalam tabel 7 sebagai berikut:

Tabel 7

SWOT SDM Kulon Progo

\begin{tabular}{|c|c|c|}
\hline IFAS & $\begin{array}{l}\text { (S) Strengths/ } \\
\text { Kekuatan }\end{array}$ & $\begin{array}{l}\text { (W) Weaknesses/ } \\
\text { Kelemahan }\end{array}$ \\
\hline \multirow{3}{*}{$\begin{array}{l}\text { (O) Opportunities/ } \\
\text { Peluang }\end{array}$} & Strategi SO & Strategi WO \\
\hline & $\begin{array}{l}\text { 1. Adanya sinergy dari PHRI dan } \\
\text { pemerintah untuk memberikan } \\
\text { bimtek bagi usaha jasa pariwisata } \\
\text { baik akomodasi perhotelan } \\
\text { maupun rumah makan. }\end{array}$ & $\begin{array}{l}\text { 1. Menjalin kerjasama dengan } \\
\text { perguruan tinggi swasta untuk } \\
\text { memberikan beasiswa kepada } \\
\text { masyarakat Kulon Progo yang } \\
\text { hendak melanjutkan studi }\end{array}$ \\
\hline & $\begin{array}{l}\text { 2. Melaksanakan pelatihan yang } \\
\text { bekerjasama dengan dinas tenaga }\end{array}$ & $\begin{array}{l}\text { 2. Bekerjasama dengan dinas } \\
\text { pariwisata Kulon Progo untuk }\end{array}$ \\
\hline
\end{tabular}




\begin{tabular}{|c|c|c|}
\hline EFAS & $\begin{array}{l}\text { (S) Strengths/ } \\
\text { Kekuatan }\end{array}$ & $\begin{array}{l}\text { (W) Weaknesses/ } \\
\text { Kelemahan }\end{array}$ \\
\hline & $\begin{array}{l}\text { kerja berupa pelatihan barista, } \\
\text { dan pelatihan chef. }\end{array}$ & $\begin{array}{l}\text { mengadakan pelatihan hotel } \\
\text { system dan digital marketing. }\end{array}$ \\
\hline $\begin{array}{l}\text { (T)Threats/ } \\
\text { Ancaman }\end{array}$ & \begin{tabular}{|l}
\multicolumn{2}{|c}{ Strategi ST } \\
1. Bekerjasama dengan pemda \\
setempat didalam penataan \\
lingkungan sekitar, terutama \\
usaha-usaha yang tidak terkena \\
dampak pengembangan. \\
2. Pemerintah membuat kebijakan \\
agar pihak asing tidak menguasai \\
pariwisata di Kulon progo.
\end{tabular} & $\begin{array}{l}\text { Strategi WT } \\
\text { 1. Proses permohonan pembuatan } \\
\text { TDUP akan dibantu } \\
\text { sepenuhnya oleh Dinas } \\
\text { Penanaman Modal Pelayanan } \\
\text { Ijin Terpadu yang ada di } \\
\text { Kabupaten Kulon Progo. } \\
\text { 2. Promosi dan pemasaran yang } \\
\text { efektif dan efisien sehingaa } \\
\text { mampu menjaring wisatawan } \\
\text { dalam negeri hingga luar } \\
\text { negeri. }\end{array}$ \\
\hline
\end{tabular}

Sumber: Olahan Peneliti (2019)

Berdasarkan matrik SWOT tersebut, hasil analisis terpetakan pada kuadran I (positif, positif), posisi ini menandakan kondisi yang kuat dan berpeluang. Rekomendasi strategi yang diberikan adalah progresif, sehingga sangat dimungkinkan untuk terus melakukan ekspansi. Untuk itu, strategi yang dapat digunakan berfokus pada strategi SO. Strategi SO digunakan untuk memanfatkan peluang dengan memaksimalkan kekuatan agar dapat berkembang di masa depan. Strategi progresif (SO) untuk memanfaatkan peluang seperti yang telah digambarkan dalam tabel SWOT yaitu:

\section{Jangka Pendek}

Dalam jangka pendek, dilakukan pelatihan berupa bimtek perijinan secara online melalui online single submission (OSS) bagi usaha jasa pariwisata baik akomodasi perhotelan maupun rumah makan.

2. Jangka menengah

Upaya yang dilakukan dengan melaksanakan pelatihan yang bekerjasama dengan dinas tenaga kerja berupa pelatihan barista, dan pelatihan chef. Pelatihan ini berlangsung selama dua puluh hari dengan anggaran dari dinas terkait. Pelatihan yang dilaksanakan yaitu: cara memasak dengan baik dan benar, cara melayani pelanggan dengan baik, pelatihan menyajikan makanan, peningkatan SDM kuliner, pengurusan BPOM, bimtek ketahanan pangan, pelatihan roasting, pelatihan basic barista (menggunakan mesin), pelatihan marketing menggunakan sosial media, layak higienis dan sanitasi.

3. Jangka Panjang

Dalam jangka Panjang akan dilakukan uji kompetitif, bimtek usaha jasa pariwisata, international workshop, pelabelan dan digital marketing bagi usaha perhotelan dan restoran.

\section{KESIMPULAN}

Berdasarkan pembahasan di atas dapat disimpulkan bahwa:

1. Masyarakat sangat setuju dengan dibangunnya YIA, masyarakat merelakan tanahnya untuk dijadikan bandara. Selain itu, peningkatan pelanggan di rumah makan dan restoran juga dirasakan oleh masyarakat sekitar.

2. Strategi pengembangan pariwisata kawasan Airport City di Kabupaten Kulon Progo dilakukan dengan membentuk BPC 
Temoteus Prasetyo Hadi Atmoko, Ihsan Budi Santoso: STRATEGI PENGEMBANGAN

KAWASAN AIRPORT CITY MELALUI PENINGKATAN SDM PERHOTELAN DAN

RESTORAN DI KABUPATEN KULON PROGO

PHRI Cabang Kulon Progo. Dengan pembentukan PHRI Cabang Kulon Progo ini berdampak pada pertumbuhan hotel dan restoran yang ada di Kulon Progo.

3. Strategi PHRI dalam meningkatkan Sumber Daya Manusia bidang Perhotelan dan Restoran berfokus pada strategi SO, yaitu dengan:

a. Bantuan berupa bimtek bagi usaha jasa pariwisata baik akomodasi perhotelan maupun rumah makan dalam hal perijinan.

b. Melaksanakan pelatihan yang bekerjasama dengan dinas tenaga kerja berupa pelatihan barista dan pelatihan chef.

\section{DAFTAR PUSTAKA}

---------Undang-Undang Kepariwisataan no 10 tahun 2009. Jakarta.

Atmoko, Presetyo Hadi \& Heni, Widyaningsih. (2018). Manajemen dan Bisnis Perhotelan. Yogyakarta: Explore.

Gaol, L Jimmy. (2014) A to Z Human Capital (Manajemen Sumber Daya Manusia) Konsep, Teori, dan Pengembangan dalam Konteks Organisasi Publik dan Bisnis. Jakarta: PT Gramedia Widiasarana.

Peraturan Menteri Pariwisata Dan Ekonomi Kreatif Republik Indonesia Nomor 11 Tahun 2014 Tentang Standar Usaha Restoran.

Rofaida, Rofi. (2013). Model Peningkatan Kompetensi Sumber Daya Manusia Pada Sektor Pariwisata di Kota Bandung Sebagai Upaya Meningkatkan Daya Saing Sektor Pariwisata. Jurnal Manajemen Bisnis Indonesia, Vol 1 No 1. UPI, hal. 127146.

Sujatno, Bambang. (2009). Hotel Courtesy. Yogyakarta : Andi Offset.

Sutrisno, Edy. (2014). Manajemen Sumber Daya Manusia. Jakarta: Pranada Media Group.
Tanuwijaya, Linandar. (2015). Peningkatan Kompetensi SDM Bidang Tata Hidangan Melalui Pelatihan Pada Usaha akomodasi Hotel Bintang Tiga di Kabupaten Bogor. Jurnal BARISTA, Vol 2 No 1. STP Bandung, hal. 18-34.

Utama, Rai. (2012). Metodologi penelitian Pariwisata dan Perhotelan. Yogyakarta: Andi.

Widiastuti.http://krjogja.com/web/news/read/ 54622/BPC_PHRI_Kulonprogo_Dilant ik, diakses pada tanggal 14 Agustus 2018.

Widyaningsih, Heni. (2013). Partisipasi Hotel Menyajikan Makanan Tradisional Untuk Memperkenalkan Kuliner Yogyakarta. Jurnal Khasanah Ilmu Vol. 4 No 2, hal. 49-56. 